\title{
TECHNOLOGICAL ASSIMILATION AND DIVERGENCE IN TIMES OF CRISIS
}

\author{
Isabel ÁLVAREZ, Debora DI CAPRIO, Francisco Javier SANTOS-ARTEAGA \\ Universidad Complutense de Madrid, Madrid, Spain
}

Received 12 December 2012; accepted 29 September 2013

\begin{abstract}
We study an endogenous stochastic growth model whose dynamic evolution is determined by an adaptive learning process defining the accumulation of technological knowledge within countries. Both the assimilation of technological knowledge and the arrival rate of innovations depend on the technological development level of countries. We illustrate how heterogeneous levels of technological development provide laggard countries with insufficient innovation incentives, leading to divergences in total factor productivity and their technological stagnation. The model is simulated numerically using data from the current Innovation Union Scoreboard where the main expected growth patterns of the Baltic States are compared to those of the reference innovators within the European Union area.
\end{abstract}

Keywords: technology assimilation, learning, stochastic growth, national innovation system, technological development, economic crisis, Baltic states, European Union.

JEL Classification: O31, O33.

\section{Introduction}

The introduction and assimilation of new technologies by firms and countries, as well as their innovation and manufacturing processes, require the existence of a skilled labor force and a developed technological infrastructure or national system of innovation. This infrastructure, whose quality is determined, among others, by the existence of techno-economic webs and industrial districts (Furman et al. 2002), limits the ability of firms and countries to innovate and learn through manufacturing, since it must develop simultaneously to the knowledge acquired by workers in order to be implemented efficiently (López et al. 2011). Such a constraint implies that innovation and manufacturing require both a continuous learning process among workers as well as the existence of a solid technological base at the country level. In particular, when dealing with technological diffusion processes, it is generally understood

Corresponding author Francisco Javier Santos-Arteaga

E-mail: fransant@ucm.es 
that knowledge does not flow immediately among workers, firms and countries but diffuses following an endogenously determined sigmoid accumulation function.

The processes of technological development and economic growth require the building of absorptive capacities in order for countries to master any imported technological knowledge. The absorptive capacity of countries is based mainly on their learning capacity, which, at the same time, depends on the quantity and quality of the R\&D performed and their stock of human capital (Niosi 2010). It should be noted that the evolution of technological development is quite a complex process as it simultaneously involves economic, social, and managerial actors (Magruk 2011). Examples of this type of processes can be found in the literature at different levels of disaggregation such as the organizational (Domijan, M., Domijan, E. 2008), cluster (Zeng et al. 2010), and industry (Castellacci 2006), ones. The complex nature of technological knowledge and its diffusion dynamics have also been widely studied [and verified] by evolutionary economists (Silverberg et al. 1988; Chiaromonte et al. 1993; Patel, Pavitt 1998). Refer to Fagerberg et al. (2005) and Hanusch and Pyka (2007) for recent reviews of the literature on this topic.

Moreover, long run financial consequences usually follow from the processes of technological development and economic growth, see Pilinkus (2010) for an illustration of this phenomenon among the Baltic States. In this sense, the financial sector complements the cumulative pattern of innovation activities, where differences in innovation strategies among firms and countries determine their probability to repeatedly innovate (Clausen et al. 2012). Similarly, the access to market-based finance has been shown to be beneficial for the generation and development of technological activities among small and medium sized enterprises (Wang, Shen 2007). This is particularly important when considering catching-up and technology learning processes, since, in most cases, catching-up cannot be fulfilled in one technology lifecycle and technological paradigms shift faster with the progress of science and technology ( $\mathrm{Li}, \mathrm{Wu} 2002)$.

In the same way, several cross-country studies have illustrated a virtuous circle in which R\&D spending, innovation, productivity, and per capita income mutually reinforce each other and lead countries to long-term sustained growth rates (Hall, Jones 1999; Rouvinen 2002; Aghion, Howitt 2007). At the firm level, there is evidence showing the positive links between R\&D, innovation, and productivity for industrialized countries (Griffith et al. 2004; OECD 2009; Castellacci, Zheng 2010; Mairesse, Mohnen 2010). That is, firms investing in knowledge are generally more able to introduce new technological advances and those that innovate have greater labor productivity than those that do not. The resulting increments in productivity highlight the importance of innovation in enabling firms to improve their economic performance and catch up. In particular, several empirical analysis illustrate how technological innovations, both product and process, lead to superior economic performance among European firms (Loof, Heshmati 2002; Mohnen et al. 2006; Van Leeuwen, Klomp 2006).

When dealing with the evidence regarding the ability of firms to transform R\&D into innovation in developing economies, the results are much more mixed than in the case of firms in industrialized countries (Silva, Teixeira 2011). A positive relation between R\&D, innovation, and productivity has been found for newly industrialized Asian countries, see 
Crespi and Zuniga (2012) for a review of the literature. These authors also illustrate how the Latin American evidence is much more mixed, which may result from the biased specialization of several of these countries in favor of industries featuring low domestic knowledge generation (Cimoli, Katz 2003). The development of knowledge-based economies and technological innovations within the Eastern European region has also led to mixed results, see Huggins and Strakova (2012) for the Balkan Peninsula, Svetlicic et al. (2007) for several Central European countries, and Masso and Vather (2008) for Estonia.

The importance of human capital accumulation as a source of economic growth within a technological oriented environment has been repeatedly emphasized in the economic literature (Olsson 2005; Gupta, Chakraborty 2006; Arcalean et al. 2012). The European experience is documented both for technological leaders such a Sweden (Ballot, Taymaz 1997), and transitional economies like Croatia (Skare 2011). A wider perspective is provided by Fagerberg et al. (1997), who illustrate how innovation and the diffusion of technology were indeed essential factors behind the European growth of the 1980s. However, due to a lack of own R\&D capabilities, most poor regions failed to take advantage of the more advanced technologies available elsewhere. As a result, economic growth in the poorer regions was not substantially faster than in the richer ones, where growth was triggered by much larger R\&D efforts and a more advanced industrial structure.

The current paper concentrates on the effects that the assimilation of technological knowledge and the innovation incentives that result from it have for the economic growth of countries. Countries [and the firms located within them] will be assumed to assimilate the knowledge implicit in innovations through an adaptive learning process determining their accumulation of technology and infrastructures. The technological knowledge and infrastructures accumulated by a country, i.e. its national innovation system, will, at the same time, determine the manufacturing productivity of the newly acquired technology, as well as its ability to obtain additional knowledge and develop further innovations. These premises are built into a stochastic endogenous growth model that will be used to analyze the expected technological evolution of a selected group of countries within the heterogeneous group composing the Euro-27 economic area. In particular, its dynamic implications regarding the economic evolution of the Baltic states within this group will be simulated using data from the latest Innovation Union Scoreboard (European Commission 2011). The main conclusion obtained states that technological laggard countries require exogenous and sufficiently large incentives in order to consistently develop their national systems of innovation through time. Otherwise, laggards will eventually stagnate both in technological and productivity terms as their national innovation systems become progressively obsolete.

The paper proceeds as follows. Section 1 introduces the model and derives the optimal behavior of [firms and] countries. Section 2 analyzes numerically these normative results and concludes.

\section{Cumulative technological processes}

Consider an economic area consisting of two groups of countries and a finite number of firms per country. Countries are characterized by a unique industrial sector with a finite 
number of firms in it. This unique sector may be intuitively identified with the national system of innovation of each country, a concept developed by Lundvall (1988). Alternatively, we could generalize this setting allowing for several industrial sectors within each country. Increasing the number of industrial sectors would allow us to analyze the sectoral specialization of countries but would not affect the main results obtained while complicating the presentation considerably.

The exchange rate is fixed equal to one and identical unitary prices are assumed in both groups of countries for the most technologically advanced good being produced. There are always $N$ workers per firm in each country. That is, we will not be studying migratory patterns between countries or their consequences. The labor force is composed exclusively by skilled workers, who can be used to either innovate or manufacture, $n_{s n}$ and $n_{s m}$, respectively, such that $n_{s n}+n_{s m}=1$. However, human capital formation processes differ among countries, which constitutes a source of heterogeneity affecting their respective technological assimilation and subsequent growth patterns.

If labor is used to manufacture it generates output per time period at a rate limited by the level of technological development achieved by the country:

$$
\xi=\frac{\lambda^{c}}{\lambda^{*}}
$$

which reflects the distance existing among countries within a particular technological paradigm. That is, $\lambda^{*}$ indicates the level of technological development necessary to generate the latest innovation available, i.e. the technological frontier, while $\lambda^{c}$ stands for the level achieved by the country. If labor is used to innovate, it increases the probability of achieving a higher level of technological development the following period. All workers receive the same wage, $w$, independently of whether they are hired to manufacture or innovate. We will relax this latter assumption and analyze in detail its effect on the convergence process of countries in Section 2.

Time is continuous and measured by [discrete] innovations, such that one unit of time lasts as much as it is required for the next innovation to appear. Similarly to Aghion and Howitt (1992), if two innovations occur simultaneously it is assumed that continuity allows for them to be separated in two different units of time. At a given point in time, one of the firms within a country develops an innovation while the remaining ones behave as laggards. Contrary to the neoclassical economic literature on quality ladders (Grossman, Helpman 1991), it will be assumed that all firms in both groups of countries gain immediate access to the most advanced production technology. As a result, all firms in both groups of countries charge the same quality adjusted [unitary] price for the latest state of the art good being produced. Innovation incentives are provided by infinitely elastic demand functions in each country that absorb all the production of the good per time period. Thus, innovations do not generate technological monopolies, but provide a factor productivity advantage over the rest of the firms. López et al. (2011) illustrate within a similarly constrained model the specific economic incentives of the firms located within both groups of countries to develop innovations.

The above simplifications have been imposed to emphasize the central role that national systems of innovation [total factor productivity differentials] have in the economic growth 
process of countries (Furman et al. 2002). In particular, note that the $\xi$ variable has been assumed to include all financial, political and institutional factors affecting economic growth. Clearly, disaggregating $\xi$ and allowing for frictions within any of these sectors or the linkages existing among them would lead to a decrease in the respective $\xi$ values achieved by countries.

Countries must design their national systems of innovation by distributing their skilled labor force between manufacturing and innovation activities. In doing so, they maximize the expected flow of profits obtained from their firms limited by their respective levels of technological development:

$$
\Pi(t)=E \int_{t}^{\infty} e^{-\rho[\tau-t]} \pi\left(n_{s m} \mid \xi\right) d \tau,
$$

where:

$$
\pi\left(n_{s m} \mid \xi\right)=\xi^{1-\alpha} K^{\alpha} n_{s m}^{1-\alpha}-w\left(n_{s n}+n_{s m}\right)
$$

and $\rho$ represents the rate of time preference for any given firm, assumed identical both among firms and between groups of countries. The level of technological development of a country determines the productivity of its labor for a given amount of physical capital $K$. Thus, the most productive technology available can only be exploited up to the limit imposed by the technological development level of the country. National systems of innovation, for which $\xi$ is a proxy, constrain both the productivity of the production factors and the learning capacity of skilled workers. The latter one is assumed to determine the innovation probability of a country within the current setting.

Innovations are governed by a Poisson process whose arrival rate is defined by:

$$
\theta_{\xi}=\frac{1}{1+\left(\frac{1}{n_{s n}}-1\right) e^{-\mu(\xi, h) N}},
$$

where $\mu(\xi, h)=\xi h$ stands for the absorptive capacity of manufacturing workers, i.e. their ability to learn, with $\mu^{\prime}(\xi)>0$ and $h$ referring to the human capital accumulated by skilled workers. This learning function accounts for the fact that manufacturing workers are able to acquire the tacit knowledge implicit in the most technologically advanced good through both their capacity to learn and direct knowledge spillovers from innovator workers. Depending on the initial proportion of innovator workers and the absorptive capacity of the manufacturing ones, there will be a $\theta_{\xi}$ proportion of innovator workers at the end of a given time period, determining the arrival probability of the next innovation. Henceforth, we will refer to the most technologically developed country as the innovator country.

Equation (2) corresponds to a logistic learning function commonly used by the evolutionary economic literature to analyze technological diffusion processes, see Aghion and Howitt (1999) and Geroski (2000) for a review of this literature. In this regard, $\theta_{\xi}$ could be interpreted as an incremental [cumulative] innovation process that becomes radical after reaching a value of one, giving place to a new technological cycle. Note also that this equation accounts for the learning process that takes place among workers but does not consider the one taking place among the firms located within a given industrial cluster, see Aghion and Howitt (1999) for a standard textbook approach to the latter. We omit this second process 
here and assume that all effects regarding national innovation systems and their differences among countries are summarized by $\xi$.

The stochastic evolution of $\xi$ per innovation unit of time depends on its current value and the Poisson process defining the innovation arrival rate. The increase in the level of technological development of a country if an innovation takes place among any of its firms equals:

$$
d \xi=(\gamma \xi-\xi) d z_{\xi},
$$

with $\gamma>1$ and where the arrival rate of the corresponding Poisson process, $z_{\xi}$, is determined by $\theta_{\xi}$. The stochastic differential equation defining the evolution of $\xi$ among laggard countries reads as follows:

$$
d \xi=\left[\frac{\pi\left(n_{s m} \mid \xi\right)}{\pi\left(n_{s m} \mid \bar{\xi}\right)}\right] d t+(\gamma \xi-\xi) d z_{\xi}
$$

where $\bar{\xi}$ represents the technological development level of the innovator country. That is, all profits are assumed to be invested by each country in the improvement of their relative levels of technological development, with laggard countries being able to invest a smaller amount than the innovator one.

\section{Optimality}

Countries have to distribute their resources between both labor types after each innovation takes place, while being constrained by their relative levels of $\xi$ and $\theta_{\xi}$. It should be noted that, even though manufacturing activities require human capital to exploit the leading technology, their effect on the production function of the country is only temporal. That is, for a country to generate the technological base required to grow through time it must innovate continuously.

The Bellman equation defining the intertemporal optimization problem of a laggard country is given by:

$$
\rho V(\xi)=\max _{n_{s n}, n_{s m}} \pi\left(n_{s m} \mid \xi\right)+V_{\xi}(\xi)\left[\frac{\pi\left(n_{s m} \mid \xi\right)}{\pi\left(n_{s m} \mid \bar{\xi}\right)}\right]+\theta_{\xi}[V(\gamma \xi)-V(\xi)],
$$

which allows for a direct comparison between the immediate benefits obtained from manufacturing activities and the expected benefits derived from innovation. Manufacturing activities generate immediate profits for the country, $\pi\left(n_{s m} \mid \xi\right)$, and lead to a deterministic increase in $\xi$, whose marginal value is accounted for by $V_{\xi}(\xi)$. However, the effect that manufacturing activities have on $\xi$ via profits must be weighted with respect to the corresponding profits obtained by the innovator country, $\pi\left(n_{s m} \mid \bar{\xi}\right)$. On the other hand, the expected benefits from developing an innovation consist of the Poisson arrival rate $\theta_{\xi}$ times the value increase derived from the resulting change in $\xi,[V(\gamma \xi)-V(\xi)]$. The above Bellman equation as well as the one corresponding to the most technologically developed country can be easily derived following the guidelines introduced in the Appendix B of López et al. (2011). 
The first order conditions defining the behavior of laggard countries can be simplified in order to obtain a break up rule determining the optimal allocation of skilled labor between manufacturing and innovative activities based on the respective values of $\xi$ :

$$
\frac{n_{s m}^{\alpha}}{\left(n_{s n} e^{\mu(\xi, h) N}+1-n_{s n}\right)^{2}}=\frac{(1-\alpha) \xi^{1-\alpha} K^{\alpha}\left(1+\frac{V_{\xi}(\xi)}{\pi\left(n_{s m} \mid \bar{\xi}\right)}\right)}{e^{\mu(\xi, h) N}[V(\gamma \xi)-V(\xi)]} .
$$

The numerator within the right hand side of equation (5) corresponds to the instantaneous gains obtained from manufacturing activities. These gains are given by the marginal productivity derived from using [an additional unit of] skilled labor in manufacturing activities and the marginal value generated by $\xi$ relative to the manufacturing profits obtained by the innovator country. The denominator defines the expected gain (through the marginal probability increment induced by the respective learning processes) from using (an additional unit of] skilled labor in innovative activities.

The optimal behavior of laggard countries as well as their technological evolution and corresponding growth processes are therefore determined by the relative strength of the manufacture and innovation enhancing effects defining the right hand side of equation (5). It should be noted that the $V_{\xi}(\xi)$ term is not part of the first order conditions defining the behavior of the innovator country. These conditions lead to the following version of equation (5):

$$
\frac{n_{s m}^{\alpha}}{\left(n_{s n} e^{\mu(\xi, h) N}+1-n_{s n}\right)^{2}}=\frac{(1-\alpha) \xi^{1-\alpha} K^{\alpha}}{e^{\mu(\xi, h) N}[V(\gamma \xi)-V(\xi)]} .
$$

\section{Empirical analysis and numerical simulations}

The optimization results obtained above are sensitive to the type of value function under consideration, that is, to the section of the technological cycle through which countries evolve. We use data from the Innovation Union Scoreboard 2011 to simulate the main implications derived from the current model for the development and innovation processes taking place among various reference countries within the Euro-27 group, with particular emphasis being placed on the Baltic states. We have concentrated on the countries determining the main industrial patterns within the European group, that is, the reference innovator, Sweden, together with Germany, plus the Baltic states, all compared to the average of the European group of 27. The main data on the European countries under consideration is introduced in the second and third columns of Table Sets 1 to 3. The SII [summary innovation index] variable calculated by the Innovation Union Scoreboard will be used as a proxy for the quality and strength of the national innovation system of each country ${ }^{1}$. The values of the human resources variable refer to the human capital capacity of each country, which, at the same time, defines the absorption capacity of the labor force when determining the innovation probability of each country.

\footnotetext{
${ }^{1}$ The calculation of and additional intuition regarding the summary innovation index variable can be found at http://ec.europa.eu/growth/industry/innovation/facts-figures/scoreboards/index_en.htm
} 
Table Set 1. Basic Convergence Pattern $[\gamma \xi=1.5 \xi]$

\begin{tabular}{lccccc}
\multicolumn{5}{c}{ Concave value setting $[\mathrm{V}(\mathrm{x})=\sqrt{\mathrm{x}}]$} \\
\hline COUNTRY & SII 2011 & $\begin{array}{c}\text { HUMAN } \\
\text { RESOURCES }\end{array}$ & $\mathrm{n}_{\mathrm{sn}}$ & $\mathrm{n}_{\mathrm{sm}}$ & $\theta_{\xi}$ \\
\hline EU27 & 0.539 & 0.563 & 0.0193 & 0.9807 & 0.2904 \\
\hline DE & 0.700 & 0.613 & 0.0228 & 0.9772 & 0.6302 \\
\hline EE & 0.496 & 0.575 & 0.0155 & 0.9845 & 0.2143 \\
\hline LV & 0.230 & 0.451 & -0.2808 & 1 & $2.8211 \mathrm{e}-004$ \\
\hline SE & 0.255 & 0.646 & -0.0827 & 1 & $5.1908 \mathrm{e}-004$ \\
\hline & $\mathbf{0 . 7 5 5}$ & $\mathbf{0 . 8 9 3}$ & $\mathbf{0 . 0 1 8 8}$ & $\mathbf{0 . 9 8 1 2}$ & $\mathbf{0 . 9 4 2 0}$ \\
\hline COUNTRY & SII 2011 & HESOURCES & n $\mathrm{n}_{\text {sn }}$ & $\mathrm{n}_{\text {sm }}$ & $\theta_{\xi}$ \\
\hline EU27 & 0.539 & 0.563 & 0.0336 & 0.9664 & 0.4196 \\
\hline DE & 0.700 & 0.613 & 0.0321 & 0.9679 & 0.7078 \\
\hline EE & 0.496 & 0.575 & 0.0301 & 0.9699 & 0.3496 \\
\hline LV & 0.230 & 0.451 & -0.2701 & 1 & $2.8211 \mathrm{e}-004$ \\
\hline LT & 0.255 & 0.646 & -0.4108 & 1 & $5.1908 \mathrm{e}-004$ \\
\hline SE & $\mathbf{0 . 7 5 5}$ & $\mathbf{0 . 8 9 3}$ & $\mathbf{0 . 0 3 6 9}$ & $\mathbf{0 . 9 6 3 1}$ & $\mathbf{0 . 9 7 0 1}$ \\
\hline
\end{tabular}

Country abbreviations: DE - Germany; EE - Estonia; EU27 - EU27; LT - Lithuania; LV - Latvia; SE - Sweden

Table set 2. Catching-up Convergence Pattern $[\gamma \xi=0.755]$

Concave value setting $[\mathrm{V}(\mathrm{x})=\sqrt{\mathrm{x}}]$

\begin{tabular}{|c|c|c|c|c|c|}
\hline COUNTRY & SII 2011 & $\begin{array}{c}\text { HUMAN } \\
\text { RESOURCES }\end{array}$ & $\mathrm{n}_{\mathrm{sn}}$ & $\mathrm{n}_{\mathrm{sm}}$ & $\theta_{\xi}$ \\
\hline EU27 & 0.539 & 0.563 & 0.0126 & 0.9874 & 0.2097 \\
\hline $\mathrm{DE}$ & 0.700 & 0.613 & 0.0014 & 0.9986 & 0.0929 \\
\hline $\mathrm{EE}$ & 0.496 & 0.575 & 0.0170 & 0.9830 & 0.2305 \\
\hline LV & 0.230 & 0.451 & -0.0541 & 1 & $2.8211 \mathrm{e}-004$ \\
\hline LT & 0.255 & 0.646 & 0.0356 & 0.9644 & 0.1609 \\
\hline SE & 0.755 & 0.893 & 0.0188 & 0.9812 & 0.9420 \\
\hline \multicolumn{6}{|c|}{ Convex value setting $\left[\mathrm{V}(\mathrm{x})=\mathrm{x}^{2}\right]$} \\
\hline COUNTRY & SII 2011 & $\begin{array}{c}\text { HUMAN } \\
\text { RESOURCES }\end{array}$ & $\mathrm{n}_{\mathrm{sn}}$ & $\mathrm{n}_{\mathrm{sm}}$ & $\theta_{\xi}$ \\
\hline EU27 & 0.539 & 0.563 & 0.0234 & 0.9766 & 0.3325 \\
\hline $\mathrm{DE}$ & 0.700 & 0.613 & 0.0028 & 0.9972 & 0.1702 \\
\hline EE & 0.496 & 0.575 & 0.0325 & 0.9675 & 0.3678 \\
\hline LV & 0.230 & 0.451 & 0.1812 & 0.8188 & 0.3844 \\
\hline LT & 0.255 & 0.646 & 0.1590 & 0.8410 & 0.4954 \\
\hline SE & 0.755 & 0.893 & 0.0369 & 0.9631 & 0.9701 \\
\hline
\end{tabular}

Country abbreviations: DE - Germany; EE - Estonia; EU27 - EU27; LT - Lithuania; LV - Latvia; SE - Sweden 
Table set 3. Full Catching-up Convergence Pattern $[\gamma \xi=2 \times 0.755=1.51]$

\begin{tabular}{lccccc}
\multicolumn{5}{c}{ Concave value setting $[\mathrm{V}(\mathrm{x})=\sqrt{\mathrm{x}}]$} \\
\hline COUNTRY & SII 2011 & $\begin{array}{c}\text { HUMAN } \\
\text { RESOURCES }\end{array}$ & $\mathrm{n}_{\mathrm{sn}}$ & $\mathrm{n}_{\mathrm{sm}}$ & $\theta_{\xi}$ \\
\hline EU27 & 0.539 & 0.563 & 0.0684 & 0.9316 & 0.6042 \\
\hline EE & 0.700 & 0.613 & 0.0386 & 0.9614 & 0.7457 \\
\hline LV & 0.496 & 0.575 & 0.0760 & 0.9240 & 0.5876 \\
\hline LT & 0.230 & 0.451 & 0.1137 & 0.8863 & 0.2658 \\
\hline SE & 0.255 & 0.646 & 0.1381 & 0.8619 & 0.4542 \\
\hline & $\mathbf{0 . 7 5 5}$ & $\mathbf{0 . 8 9 3}$ & $\mathbf{0 . 0 2 5 9}$ & $\mathbf{0 . 9 7 4 1}$ & $\mathbf{0 . 9 5 7 5}$ \\
\hline COUNTRY & & Convex value setting $\left[\mathrm{V}(\mathrm{x})=\mathrm{x}^{2}\right]$ & & \\
\hline EU27 & & HUMAN & $\mathrm{n}_{\mathrm{sn}}$ & $\mathrm{n}_{\mathrm{sm}}$ & $\theta_{\xi}$ \\
\hline DE & 0.539 & 0.563 & 0.1371 & 0.8629 & 0.7676 \\
\hline EE & 0.700 & 0.613 & 0.0618 & 0.9382 & 0.8279 \\
\hline LV & 0.496 & 0.575 & 0.1616 & 0.8384 & 0.7695 \\
\hline LT & 0.230 & 0.451 & 0.7129 & 0.2871 & 0.8751 \\
\hline SE & 0.255 & 0.646 & 0.5091 & 0.4909 & 0.8434 \\
\hline County & $\mathbf{0 . 7 5 5}$ & $\mathbf{0 . 8 9 3}$ & $\mathbf{0 . 0 5 7 6}$ & $\mathbf{0 . 9 4 2 4}$ & $\mathbf{0 . 9 8 1 1}$ \\
\hline
\end{tabular}

Country abbreviations: DE - Germany ; EE - Estonia; EU27 - EU27; LT - Lithuania; LV - Latvia; SE - Sweden

The fourth and fifth columns of each table set follow from solving the corresponding first order conditions of the current model for each country. The following values have been fixed through all the numerical simulations: $K=1, N=10$ and $\alpha=0.3$. These values have been chosen in order to simplify the presentation and do not affect the main results obtained. Two main remarks are however due. First, the most technologically developed country within the Euro-27 group is Sweden, i.e. it has the highest SII and Human Resources values combined, and has therefore been used as the main convergence reference. Second, the set of solutions to the first order conditions delivers both rational and irrational values. We have chosen and reported the highest one within the former group, even in the case when all the values obtained are negative. However, whenever the optimal value of $n_{s n}$ is negative, we have assigned the corresponding country a value of 0.0001 in order to allow for comparability among the probabilities within the positive real quadrant. It should be noted that these numerical results imply that the corresponding countries will be following suboptimal policies. That is, these countries are forced to allocate too high a proportion of workers to innovative activities given their underdeveloped innovation systems. This absence of innovation incentives will deepen the divergent gap with respect to the innovator countries. Such a result will be evident in the simulations displaying the evolution of the innovation probabilities where optimal negative values are initially obtained for Latvia and Lithuania, with particular emphasis on the former one.

Each set of tables represents concave and convex functional forms accounting for different value gains resulting from successful innovations. The first set of tables corresponds to the 
setting where each innovator country improves the state of its national innovation system by 1.5 times its pre-innovation level. That is, the improvements derived from an innovation are constrained by the level of $\xi$ achieved by each country. Figure 1 illustrates the substantial differences existing between the European innovator leader and the technological laggards, i.e. Latvia and Lithuania, in terms of innovation incentives and probabilities. The reward structures derived from the respective value functions do not suffice to improve the innovation capacity of laggards, which falls considerably behind those of the main innovator and the Euro-27 average. Furthermore, in order to account for the expected evolution of the innovation probabilities [and capacities] of countries in between innovations we have defined them as cumulative dynamical variables, i.e. we have added time, $t$, to the definition of the $\theta_{\xi}$ learning function. In this regard, Figure 2 represents the large divergence in innovation [cumulative] probability terms existing between the respective countries.

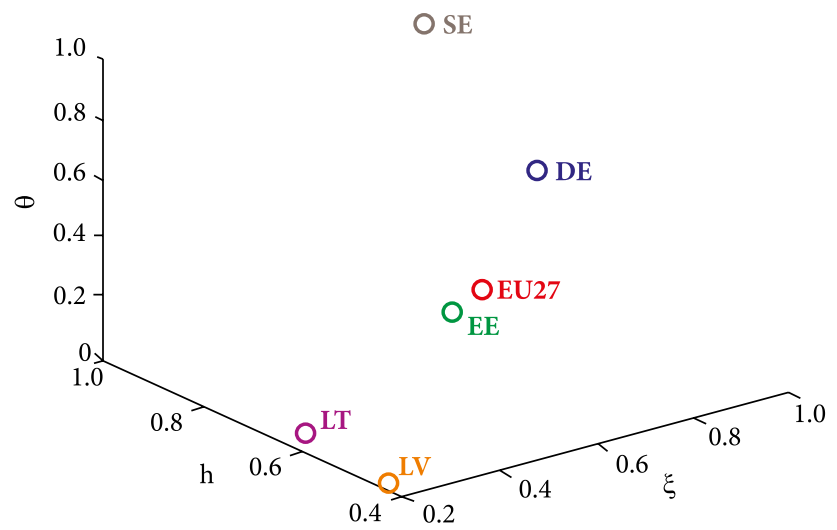

Fig. 1. Innovation probability: convex value setting $[\gamma \xi=1.5 \xi]$

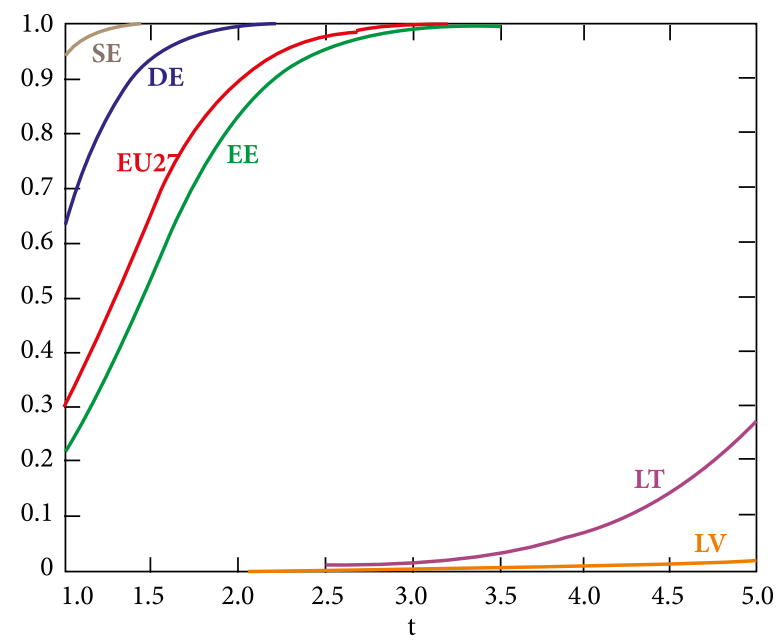

Fig. 2. Innovation probabilities evolving: concave value setting $[\gamma \xi=1.5 \xi]$ 
The remaining simulations have been included to illustrate the fundamental idea that national systems of innovation evolve cumulatively and must therefore be built and carefully developed through time. Consider the case presented in the second set of tables, where laggards reach the technological development level of the reference innovator country, i.e. 0.755 , after developing an innovation. Sweden would reach 1.5 times its pre-innovation level if it develops an innovation, as was the case in the previous setting. The resulting increase in the innovation incentives of technological laggards would lead them to allocate a larger proportion of their resources to innovative activities, an effect illustrated and emphasized by the existing differences between the convex and concave settings represented in Figures 3 and 4 , respectively.

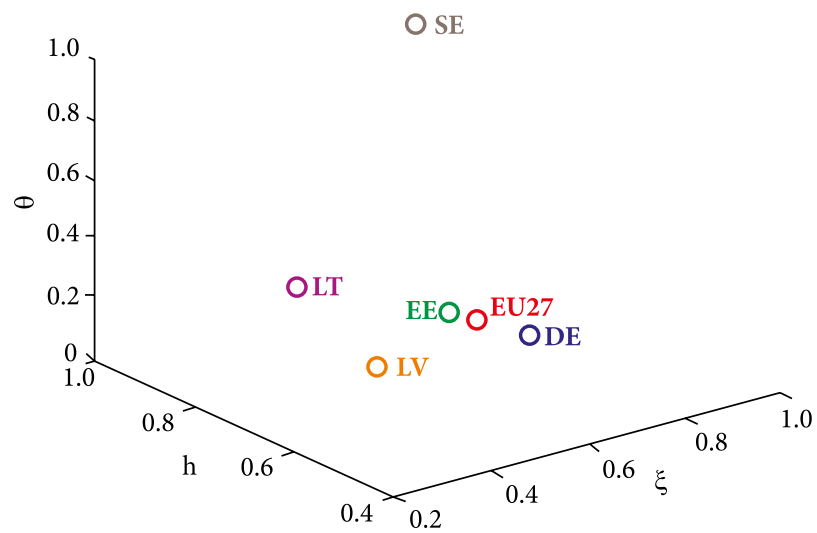

Fig. 3. Innovation probability: convex value setting $[\gamma \xi=0.755]$

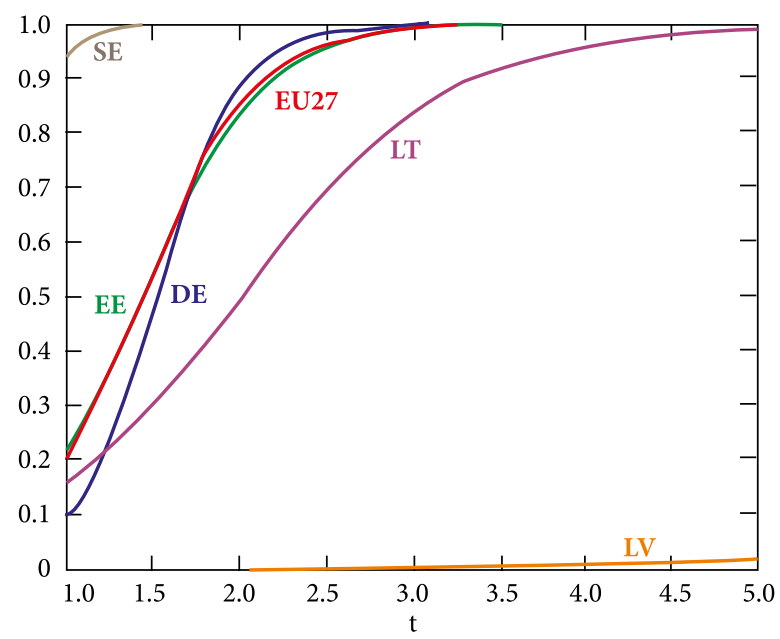

Fig. 4. Innovation probabilities evolving: concave value setting $[\gamma \xi=0.755]$ 
A similar intuition applies to the simulations described in the third set of tables, where innovators experience an increase in their factor productivity identical to that of Sweden when $\gamma=2$. That is, if a country generates an innovation, its level of technological development increases to a value of 1.51 , i.e. the level that would be attained by Sweden after innovating when $\gamma=2$. This final setting provides the largest innovation incentives to laggard countries, as can be directly inferred from Figures 5 and 6 . This is particularly the case within the convex value scenario, where innovation incentives lead both laggards to achieve an innovation probability higher than $80 \%$.

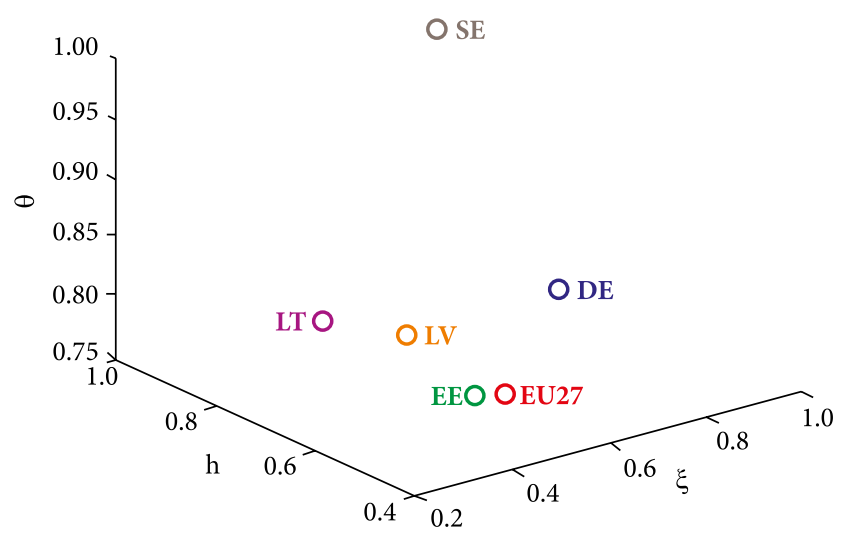

Fig. 5. Innovation probability: convex value setting $[\gamma \xi=2 \times 0.755=1.51]$

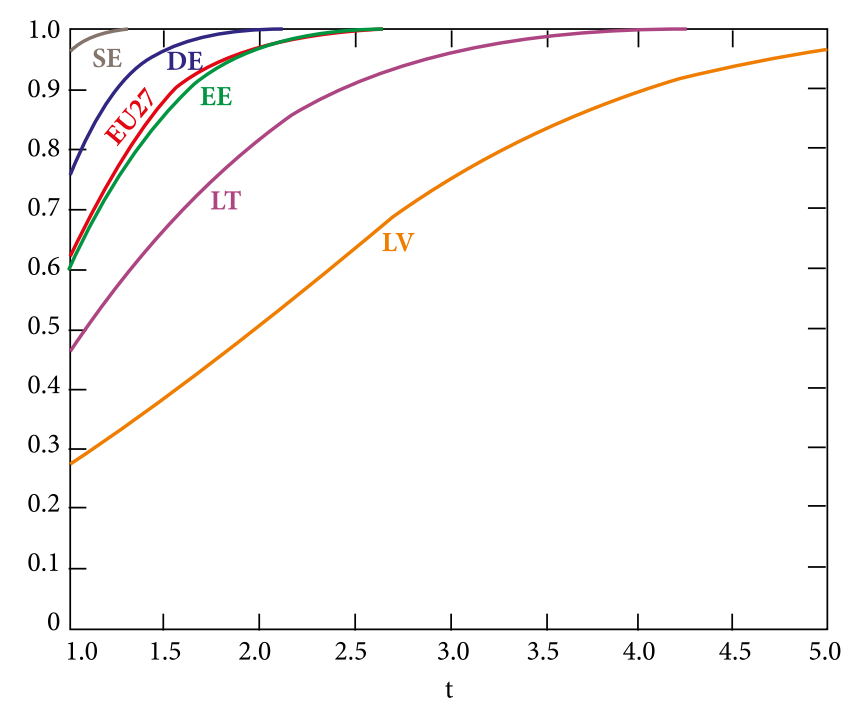

Fig. 6. Innovation probabilities evolving: concave value setting $[\gamma \xi=2 \times 0.755=1.51]$ 


\section{Alternative model specifications and divergent patterns}

Among the convergence-prone assumptions imposed when defining the current model, the absence of migration and subsequent wage simplifications deserve some additional analysis. The wages received by the skilled workers have been assumed to be identical independently of whether they are used in manufacturing or innovative activities. The intuition behind this assumption implies that since all workers are endowed with and provide the same amount of human capital, their rewards should be identical independently of the use given to them within a country. Moreover, the contribution of the manufacturing workers to the profits of a country is deterministic, while the innovative labor provides a stochastic expected return, which is based on the level of technological development of the country, a factor affecting the relative incentives of the country to assign labor to such an activity.

In order to verify the validity of our results two main variations of the model in terms of the wage received by skilled workers will be analyzed.

The first one implies allowing for migration flows to take place between both groups of countries. In this case, we should consider completely unrelated wages for skilled innovator and manufacture workers, $w_{s n}$ and $w_{s m}$, respectively. Both wages can be shown to increase in the level of technological development of a country. This result would shift the focus of the paper to the subsequent migration flows expected to be observed from the laggards to the most technologically developed country. As a result, laggards would be forced to decrease the amount (or proportion) of workers in both the innovation and manufacturing sectors in order to increment their productivity and compensate for the otherwise lower wages paid to their skilled labor. The resulting lower amounts of labor within the laggard countries would lead to lower profits and a lower innovation probability.

The second variation allows us to analyze in more detail the generation of innovation incentives and differential evolving patterns defined by the model. This second variation consists of making the wages of the innovative workers depend directly on the technological development level of the country. This dependence has already been implicitly considered through the innovation arrival probability, on which the expected return form innovative activities and the optimal allocation of labor are based. However, wages could be assumed to depend explicitly on $\xi$. In particular, the same type of analysis performed through the paper could be redone in terms of $w_{s n}=\varphi \xi w_{s m}$, with $\varphi \in(0, \infty]$. For expositional simplicity, we will assume that $\varphi=2$ through the following set of simulations. The consequences for convergence from modifying this value will become clear through the analysis of the numerical results. The corresponding optimality condition of this alternative model would be given by:

$$
\frac{n_{s m}^{\alpha}}{\left(n_{s n} e^{\mu(\xi, h) N}+1-n_{s n}\right)^{2}}=\varphi \xi \frac{(1-\alpha) \xi^{1-\alpha} K^{\alpha}\left(1+\frac{V_{\xi}(\xi)}{\pi\left(n_{s m} \mid \bar{\xi}\right)}\right)}{e^{\mu(\xi, h) N}[V(\gamma \xi)-V(\xi)]} .
$$

and similarly for the innovator country. In this alternative scenario, the direct dependence of $w_{s n}$ on $\xi$ leads to a higher proportion of [now relatively cheaper] workers being dedicated to innovative activities among the laggards. Note, however, that this is not sufficient per se to increase the innovation probability of the laggards, which depends also on $\xi$, and further 
incentives in terms of higher returns from innovation are required for laggards to experience a substantial increment in their innovation probabilities, as Figures 8 and 9 below illustrate. For comparability purposes with Figures 2, 4 and 6, the following figures concentrate on the concave value setting, with $\mathrm{V}(\mathrm{x})=\sqrt{\mathrm{x}}$.

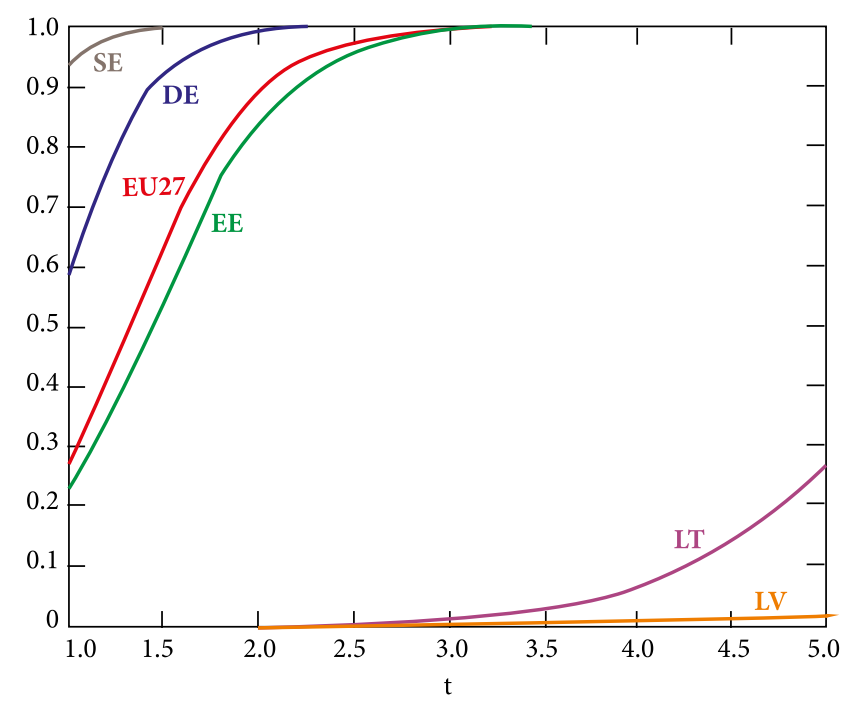

Fig. 7. Innovation probabilities evolving: concave value setting $[\gamma \xi=1.5 \xi]$

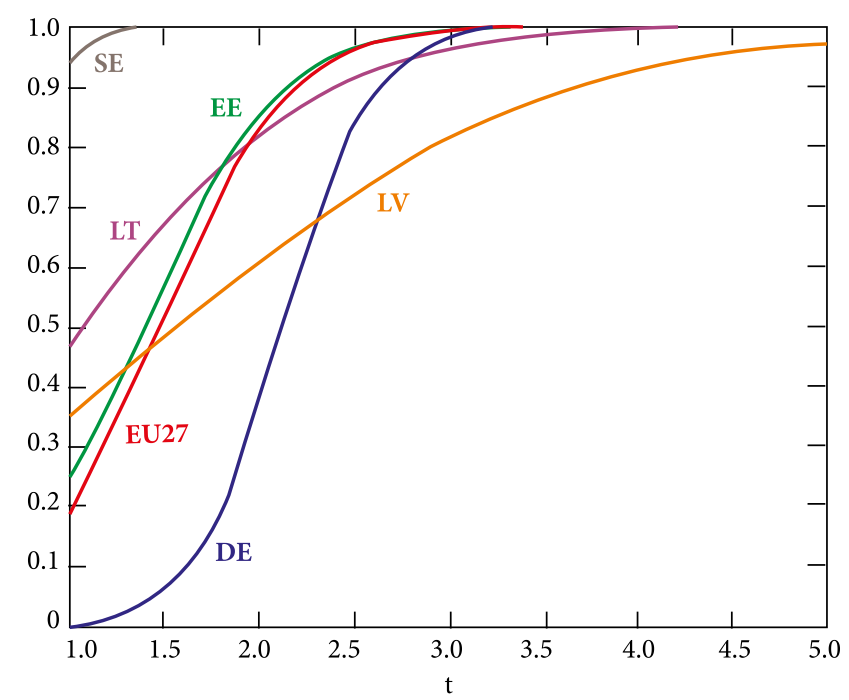

Fig. 8. Innovation probabilities evolving: concave value setting $[\gamma \xi=0.755]$ 


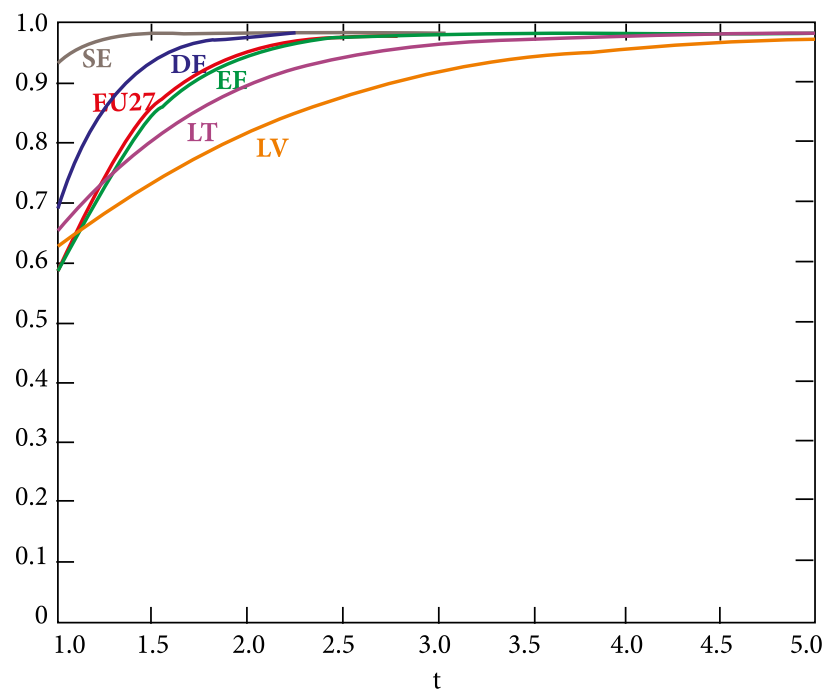

Fig. 9. Innovation probabilities evolving: concave value setting $[\gamma \xi=2 \times 0.755=1.51]$

These figures illustrate how when wages are allowed to depend directly on $\xi$, there is an increment in the incentives of the laggards to dedicate more, and now cheaper, labor to innovative activities. Thus, our original specification leads to an overpayment of the skilled innovative labor and a decrease in the optimal proportion allocated to these activities among laggard countries. However, the gains from innovative activities are based on a cumulative process and a developed technological base in terms of both human capital and infrastructures is required for a country to further develop its national system of innovation. As a result, the low levels of technological development exhibited by the laggards, with particular emphasis on Latvia and Lithuania, imply that these countries will not dedicate their resources to innovative [and $\mathrm{R} \& \mathrm{D}$ ] activities unless the required return incentives are provided. This effect becomes particularly evident when comparing the Basic Convergence Pattern presented in Figure 7 with the increment in the return incentives from innovation introduced in Figures 8 and 9 that represent the Catching-up and Full Catching-up Convergence Patterns, respectively.

\section{Conclusions and policy implications}

The importance of a developed national system of innovation for economic growth has been repeatedly emphasized both formally and empirically (Archibugi, Coco 2005; Castellacci, Archibugi 2008). However, as illustrated by the current model, the incentives to continuously develop one remain constrained by its current level. On their own, laggard countries are barely motivated by the expected returns obtained from an innovation. Thus, a sufficiently large return must be achievable in order for the laggards to start shifting resources towards the innovation, as opposed to the manufacturing, side of the system. Absent these incentives, 
we should expect to observe the long run economic stagnation of the corresponding group of [laggard] countries, as technologically developed innovators continue to improve their [cumulative] innovation systems. Note that cumulative divergences are exacerbated when laggards remain within the concave section of the technological cycle while the innovator enters the convex one, which provides relatively higher innovation incentives.

The fact of being a producer of knowledge, i.e. developing the national system of innovation, increments both the productivity of the manufacturing labor and the probability of developing an innovation within a given country. Thus, even though the most advanced technology is available to all countries, its productivity as well as the innovation probability and absorptive capacity of workers depend on the incentives of countries to invest in knowledge creation, which differ based on the rewards from innovation and the technological development level of each country.

The main welfare consequence derived from the accumulation of knowledge and technology within a given country should therefore be described in terms of its profits relative to the laggard ones. The following Eurostat-based Figures 10 and 11 illustrate this point. We are aware of the multiple factors affecting the variables presented in these figures and do not want to imply the existence of direct causality between them. However, the pictures provided by the data support the main conclusions of the model regarding the incentives of countries to invest in the development of their national systems of innovation.

Net financial assets encompass the difference between total financial assets and total liabilities. More details on the definitions of financial assets and liabilities, their categories and sub-categories are provided in http://epp.eurostat.ec.europa.eu/cache/ITY_SDDS/EN/ nasa_f_bs_esms.htm.

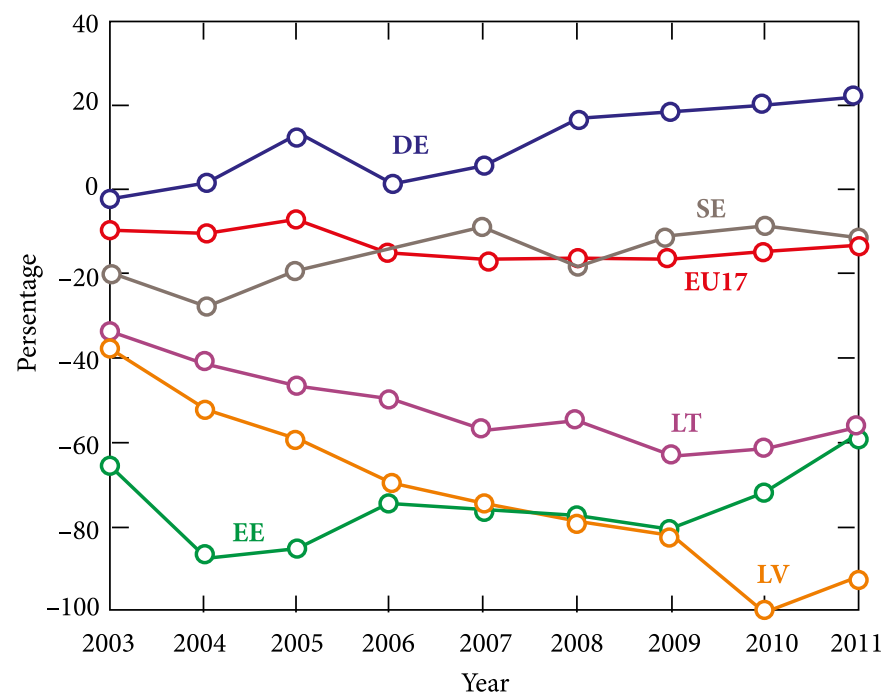

Fig. 10. [Non-consolidated] net financial assets as a percentage of GDP 


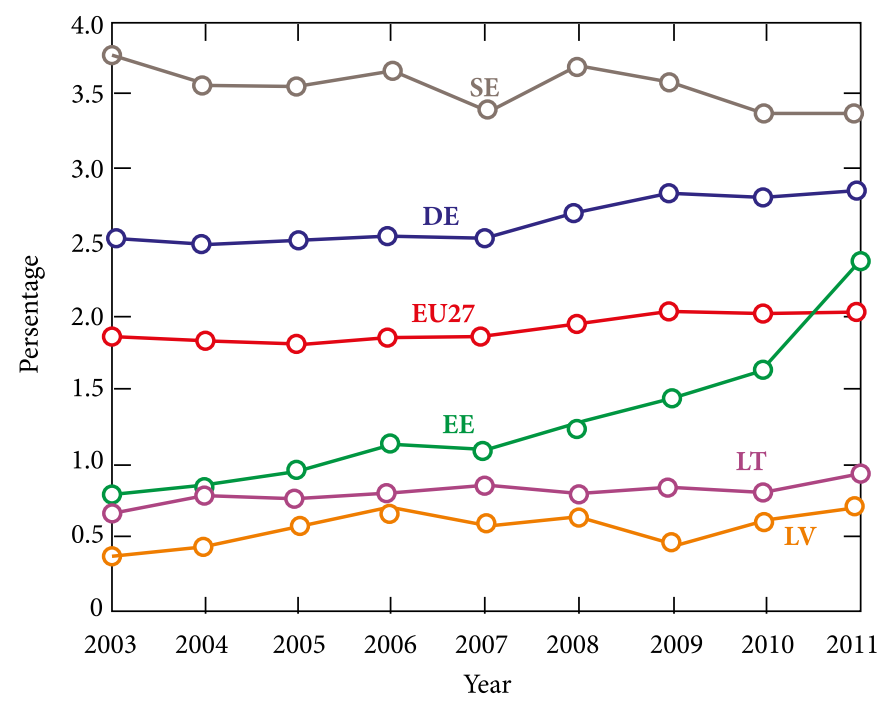

Fig. 11. Total intramural R\&D expenditure as a percentage of GDP

Eurostat statistics on R\&D expenditure are compiled using the guidelines laid out in the Frascati Manual. Refer to http://epp.eurostat.ec.europa.eu/cache/ITY_SDDS/EN/rd_esms.htm for additional information regarding this variable and its calculation.

Thus, even though the assumptions imposed in the current paper define an idealistic version of technological cooperation at the European level, additional innovation incentives are required for laggards to develop their national innovation systems. The main conclusion that follows from the paper in policy terms is that monetary incentives [in the form of direct transfers] alone may not be sufficient for laggard countries to increase the resources dedicated to innovative activities, as the previous figures illustrate. Monetary transfers may be used to ameliorate the welfare differences with the main innovators, but unless the rewards from innovation are directly shared in terms of system development and evolution, disparities will persist, even within a convergence-prone setting.

\section{References}

Aghion, P.; Howitt, P. 1992. A model of growth through creative destruction, Econometrica 60(2):323-351. http://dx.doi.org/10.2307/2951599

Aghion, P.; Howitt, P. 1999. Endogenous growth theory. MIT Press.

Aghion, P.; Howitt, P. 2007. Capital, innovation, and growth accounting, Oxford Review of Economic Policy 23(1): 79-93. http://dx.doi.org/10.1093/oxrep/grm007

Arcalean, C.; Glomm, G.; Schiopu, I. 2012. Growth effects of spatial redistribution policies, Journal of Economic Dynamics \& Control 36(7): 988-1008. http://dx.doi.org/10.1016/j.jedc.2012.01.004

Archibugi, D.; Coco, A. 2005. Measuring technological capabilities at the country level: a survey and a menu for choice, Research Policy 34(2): 175-194. http://dx.doi.org/10.1016/j.respol.2004.12.002

Ballot, G.; Taymaz, E. 1997. The dynamics of firms in a micro-to-macro model: the role of training, learning and innovation, Journal of Evolutionary Economics 7(4): 435-457.

http://dx.doi.org/10.1007/s001910050052 
Castellacci, F. 2006. Innovation, diffusion and catching up in the fifth long wave, Futures 38(7): 841-863. http://dx.doi.org/10.1016/j.futures.2005.12.007

Castellacci, F.; Archibugi, D. 2008. The technology clubs: the distribution of knowledge across nations, Research Policy 37(10): 1659-1673. http://dx.doi.org/10.1016/j.respol.2008.08.006

Castellacci, F.; Zheng, J. H. 2010. Technological regimes, Schumpeterian patterns of innovation and firmlevel productivity growth, Industrial and Corporate Change 19(6): 1829-1865. http://dx.doi.org/10.1093/icc/dtq051

Chiaromonte, F.; Dosi, G.; Orsenigo, L. 1993. Innovative learning and institutions in the process of development: on the microfoundations of growth regimes, in R. Thomson (Ed.). Learning and technological change. Palgrave Macmillan.

Cimoli, M.; Katz, J. 2003. Structural reforms, technological gaps and economic development: a Latin American perspective, Industrial and Corporate Change 12(2): 387-411.

http://dx.doi.org/10.1093/icc/12.2.387

Clausen, T.; Pohjola, M.; Sapprasert, K.; Verspagen, B. 2012. Innovation strategies as a source of persistent innovation, Industrial and Corporate Change 21: 553-585. http://dx.doi.org/10.1093/icc/dtr051

Crespi, G.; Zuniga, P. 2012. Innovation and productivity: evidence from six Latin American countries, World Development 40(2): 273-290. http://dx.doi.org/10.1016/j.worlddev.2011.07.010

Domijan, M.; Domijan, E. 2008. An organizational paradigm during technological innovation, in IEMC Europe 2008, International Engineering Management Conference, Europe, Conference Proceedings: Managing engineering, technology and innovation for growth, 28-30 June 2008, Estoril, Portugal, 217-221.

European Commission. 2011. Innovation Union Scoreboard [online], [cited 07 July 2012]. Available from Internet: http://ec.europa.eu/growth/industry/innovation/facts-figures/scoreboards/index_en.htm

Fagerberg, J.; Mowery, D. C.; Nelson, R. (Eds.). 2005. The Oxford handbook of innovation. Oxford University Press.

Fagerberg, J.; Verspagen, B.; Caniels, M. 1997. Technology, growth and unemployment across European regions, Regional Studies 31(5): 457-466. http://dx.doi.org/10.1080/00343409750132252

Furman, J.; Porter, M.; Stern, S. 2002. The determinants of national innovative capacity, Research Policy 31(6): 899-933. http://dx.doi.org/10.1016/S0048-7333(01)00152-4

Geroski, P. A. 2000. Models of technology diffusion, Research Policy 29(4-5): 603-625. http://dx.doi.org/10.1016/S0048-7333(99)00092-X

Griffith, R.; Redding, S.; Van Reenen, J. 2004. Mapping the two faces of R\&D: productivity growth in a panel of OECD industries, Review of Economics and Statistics 86(4): 883-895. http://dx.doi.org/10.1162/0034653043125194

Grossman, G.; Helpman, E. 1991. Quality ladders in the theory of growth, Review of Economic Studies 58(1): 43-61. http://dx.doi.org/10.2307/2298044

Gupta, M. R.; Chakraborty, B. 2006. Human capital accumulation and endogenous growth in a dual economy, Hitotsubashi Journal of Economics 47(2): 169-195.

Hall, R.; Jones, C. 1999. Why do some countries produce so much more output per worker than others?, The Quarterly Journal of Economics 114(1): 83-116. http://dx.doi.org/10.1162/003355399555954

Hanusch, H.; Pyka, A. (Eds.). 2007. Elgar companion to neo-Schumpeterian economics. Cheltenham: Edward Elgar. http://dx.doi.org/10.4337/9781847207012

Huggins, R.; Strakova, L. 2012. Knowledge-based economic development in emerging regions: policy issues and implications in the Balkan Peninsula, Regional Studies 46(7): 961-975. http://dx.doi.org/10.1080/00343404.2011.583912

Li, J. H.; Wu, X. B. 2002. The innovation patterns of catching-up and technology learning process, in Q. R. Xu, X. Wu, J. Chen (Eds.) Management of Technology and Innovation in the 21st Century, Proceedings: 533-536. 
Loof, H.; Heshmati, A. 2002. Knowledge capital and performance heterogeneity: a firm-level innovation study, International Journal of Production Economics 76(1): 61-85.

http://dx.doi.org/10.1016/S0925-5273(01)00147-5

López, S. M.; Molero, J.; Santos-Arteaga, F. J. 2011. Poverty traps in a frictionless world: the effects of learning and technology assimilation, Structural Change and Economic Dynamics 22(2): 106-115. http://dx.doi.org/10.1016/j.strueco.2010.12.001

Lundvall, B.-A. 1988. Innovation as an interactive process: from user-producer interaction to the national system of innovation, in G. Dosi, C. Freeman, R. Nelson, G. Silverberg, L. Soete (Eds.). Technical change and economic theory. London: Pinter.

Magruk, A. 2011. Innovative classification of technology foresight methods, Technological and Economic Development of Economy 17(4): 700-715. http://dx.doi.org/10.3846/20294913.2011.649912

Mairesse, J.; Mohnen, P. 2010. Using innovation surveys for econometric analysis, NBER working paper \# 15857. National Bureau of Economic Research, Washington, DC, United States.

Masso J.; Vather, P. 2008. Technological innovation and productivity in late transition Estonia: econometric evidence from innovation surveys. Tartu, Estonia: University of Tartu Press.

Mohnen, P.; Mairesse, J.; Dagenais, M. 2006. Innovativity: a comparison across seven European countries, NBER working paper \# 12280. National Bureau of Economic Research, Washington, DC, United States.

Niosi, J. 2010. Building national and regional innovation systems: Institutions for economic development. Cheltenham, UK, Northampton, USA: Edward Elgar. http://dx.doi.org/10.4337/9781849807050

OECD. 2009. Innovation in firms: a microeconomic perspective. Organization for Economic Cooperation and Development, Paris, France.

Olsson, O. 2005. Technological opportunity and growth, Journal of Economic Growth 10(1): 35-57. http://dx.doi.org/10.1007/s10887-005-1112-4

Patel, P.; Pavitt, K. 1998. Uneven (and divergent) technological accumulation among advanced countries: evidence and a framework of explanation, in D. Archibugi, J. Michie (Eds.). Trade, growth and technical change. Cambridge University Press. http://dx.doi.org/10.1093/0198290969.003.0009

Pilinkus, D. 2010. Macroeconomic indicators and their impact on stock market performance in the short and long run: the case of the Baltic States, Technological and Economic Development of Economy 16(2): 291-304. http://dx.doi.org/10.3846/tede.2010.19

Rouvinen, P. 2002. R\&D-productivity dynamics: causality, lags, and dry holes, Journal of Applied Economics 5(1): 123-156.

Silva, E. G.; Teixeira, A. A. C. 2011. Does structure influence growth? A panel data econometric assessment of "relatively less developed" countries, 1979-2003, Industrial and Corporate Change 20(2): 457-510. http://dx.doi.org/10.1093/icc/dtr003

Silverberg, G.; Dosi, G.; Orsenigo, L. 1988. Innovation, diversity and diffusion: a self-organisation model, The Economic Journal 98(393): 1032-1054. http://dx.doi.org/10.2307/2233718

Skare, M. 2011. How important is human capital for growth in reforming economies?, Technological and Economic Development of Economy 17(4): 667-687. http://dx.doi.org/10.3846/20294913.2011.635221

Svetlicic, M.; Jaklic, A.; Burger, A. 2007. Internationalization of small and medium-size enterprises from selected Central European economies, Eastern European Economics 45(4): 36-65. http://dx.doi.org/10.2753/EEE0012-8775450402

Van Leeuwen, G.; Klomp, L. 2006. On the contribution of innovation to multi-factor productivity growth, in B. Hall, J. Mairesse (Eds.). Empirical studies of innovation in the knowledge driven economy, Economics of Innovation and New Technologies 15(4-5): 367-390. http://dx.doi.org/10.1080/10438590500512927

Wang, L.; Shen, R. 2007. Techno-economic paradigm transformation and firm finance access evolution, in H. Zhang, R. M. Zhao, F. Hai (Eds.). Proceedings of International Conference on Enterprise Engineering and Management Innovation, 15-18 July, Wuhan University, China, 257-261. 
Zeng, S. X.; Xie, X. M.; Tam, C. M. 2010. Evaluating innovation capabilities for science parks: a system model, Technological and Economic Development of Economy 16(3): 397-413.

http://dx.doi.org/10.3846/tede.2010.25

Isabel ÁLVAREZ is Doctor in Economics, Associated Professor in Applied Economics at the Department of Economics, Universidad Complutense de Madrid. She is also research fellow at the Instituto Complutense de Estudios Internacionales. Her main research topics focus on multinational companies, the internationalisation of technology and development studies and she has several publications in technology related journals such as Industrial and Corporate Change, Technological Forecasting and Social Change, and Research Policy, among others.

Debora DI CAPRIO completed her Masters and PhD in Pure Mathematics at York University, Toronto, Canada. Her Undergraduate studies were in Mathematics at the Seconda Università degli studi di Napoli, Italy, where she has also been a Researcher and was awarded the title of Subject Expert in Geometry at the Dipartimento di Matematica. She is currently a Researcher in the Grinei and CeInnTEc Groups in Economics and Innovation Policy at the Universidad Complutense de Madrid, Spain and a Visiting Researcher at the Department of Mathematics and Statistics of York University, Canada. Her research interests focus on set-theoretical topology, utility and choice theory, information and uncertainty and she has several publications in mathematical journals, such as, Topology and its Applications, the International Journal of Strategic Decision Sciences, and the Journal of Mathematical Economics, among others.

Francisco Javier SANTOS-ARTEAGA is a researcher in the Grinei and CeInnTEc Groups in Economics and Innovation Policy at the Universidad Complutense de Madrid, Spain. He completed his PhD in Mathematical Economics at York University, Toronto, Canada, from where he also graduated with a Masters degree in Economics. Prior to this, he completed his Undergraduate studies in Economics at the Universidad de Salamanca, Spain. He was awarded grants from the Spanish Education and Culture Ministry and the European Union and also the Dean's Academic Excellence Award from York University. His research interests include systemic risk, stochastic dynamical systems and technological evolution and he has several publications in mathematical and economic journals, such as, Canadian Applied Mathematics Quarterly, Structural Change and Economic Dynamics, and the Journal of Mathematical Economics, among others. 